\title{
Human Interruption Management in Workplace Environments: An Overview
}

\author{
Mohammed Alkahtani \\ Industrial Engineering Department \\ King Saud University \\ Riyadh, Saudi Arabia \\ moalkahtani@ksu.edu.sa
}

\author{
Saber Darmoul \\ Industrial Engineering Department \\ King Saud University \\ Riyadh, Saudi Arabia \\ sdarmoul@ksu.edu.sa
}

\author{
Mustufa Haider Abidi \\ Advanced Manufacturing Institute \\ King Saud University \\ Riyadh, Saudi Arabia \\ mabidi@ksu.edu.sa \\ Shatha Samman \\ Global Assessment Inc. \\ Orlando \\ USA \\ shatha.samman@gmail.com
}

\author{
Ali Ahmad \\ Louisiana Community and Technical \\ College \\ Baton Rouge, LA, USA \\ ali.ahmad.phd@gmail.com \\ Mageed Ghaleb \\ Industrial Engineering Department \\ King Saud University \\ Riyadh, Saudi Arabia \\ mghaleb@ksu.edu.sa
}

\begin{abstract}
Interruptions are unexpected breaks that introduce new tasks on top of ongoing activities. In work environments, interruptions occur when operators and decision-makers have to deal simultaneously with several stimuli and information sources and have to make decisions so as to maintain the flow of activities at a satisfactory level of performance or quality of service. The causes and effects of interruptions and their subsequent management strategies in workplace environments have been researched in the past, however, only a few review articles are available to report on current advances in this area, to analyze contributions, and to highlight open research directions. This paper offers an up-to-date review and a framework for interruptions and interruption management strategies. The current approaches to identify, report, and manage in terruptions in a variety of workplace environments are reviewed and a description of environmental characteristics that favor the occurrence of interruptions and influence interruption management in workplace environments is provided. Various approaches to classify and model the different types of interruptions and their cause-consequence relationships are discussed and the strategies to manage interruptions and approaches to measure human performance when dealing with interruptions are analyzed. Based on these insights, several guidelines to manage interruptions in workplace environments are provided, and future research directions are highlighted.
\end{abstract}

Keywords-interruptions; interruption management strategies; workplace en vironments

\section{INTRODUCTION}

A workplace environment consists of everything that forms a part of an employee's involvement with the work itself, such as the relationships with co-workers and supervisors, working equipment and devices, working tasks, etc. Workplace environment can be any place including a home-office to a large office building or factory [1]. In several workplace environments, it is important to make sure that the trade remains competitive and prosperous [2]. Balancing between staff collaboration in workplaces and the cost of interruption is a hard question with which workplaces struggle [3]. This problem is becoming even more critical where corporations are evaluating means to escalate yield while mitigating in-house costs [4]. In [5], interruptions were defined as breaks in action that introduce new tasks, often unexpectedly and unplanned, on top of an ongoing activity. Handling interruptions is a part of interruption management, which has been defined as the detection, interpretation, and integration of interruptions within ongoing task performance [6]. Interruptions can have substantial effects on job performance and employee welfare [7]. The importance of reducing the negative consequences of interruptions in any working environment makes interruption management an important consideration. Although interruptions and interruption management have stimulated a lot of research in recent years, only a few studies address the recent advances in this field. To the best of our knowledge, the most recent review was conducted in 2010 [8], which focused on interruptions and interruption management in healthcare settings. The main findings reported were: interruptions happen regularly in all healthcare sceneries, interruptions in healthcare have only been explored from the perspective of the individual being interrupted, and few studies inspected the cognitive inferences of interruptions.

This article provides a review and a framework to analyze literature on interruptions and interruption management strategies in workplace environments. Common causes of interruptions in workplace environments are discussed, and a classification into two sections is suggested: interacting with information and communication technologies and performing office-related activities. The current approaches to identify, report, and manage interruptions are studied. Then, a description of environmental characteristics that favour the occurrence of interruptions and influence interruption management in workplace environments is provided. Finally, 
the article strategies to manage interruptions are described and analyzed and a stage model of interruption management that can be used when dealing with interruptions is proposed. The article concludes by suggesting guidelines for interruption management in workplace environments and highlighting future research directions.

\section{WORKPLACE ENVIRONMENTS}

The term workplace represents the physical location where a human is working or employed. Author in [9] classified workplaces according to personality types and occupations into realistic type work environments, investigative type work environments, artistic type work environments, social type work environments, enterprise type work environments, and conventional type work environments. A properly designed workplace assists an organization's tactical business plans, permits staff to accomplish their work competently and efficiently, symbolizes and exemplifies the ethics and beliefs of the company, and is environmentally healthy [10]. Properly designed workplaces possess the following features: interference-free work, collaborative and spontaneous interaction, concentrated teamwork and meetings, personal work style promotion, workstation personalization, customized thermal control, access to sunshine, control of brightness, clear way finding, adjacencies that support work flow, up gradation with latest technology, ergonomic accommodation, and expression of organizational culture [10]. Interruptions in a workplace may have a negative impact on well-designed workplace features. As a result, they can have a direct effect on the efficiency, well-being and safety, comfort, attentiveness, job satisfaction, and confidence of staff at the workplace. Therefore, identifying factors that result in interruptions and effective strategies to manage interruptions may reduce the negative impacts of interruptions in workplace environments. Typical workplace examples where interruptions occur are banks [11] and construction sites [12] or hearlthcare [13-15].

\section{INTERRUPTION CAUSES IN WORKPLACE ENVIRONMENTS}

Interruptions are an omnipresent part of work environments. They are a result of the need to maintain the flow of activities in the workplace, while handling with a number of stimuli and data sources at the same time [16-19]. Interruptions can be broadly classified, according to their cause, into external or internal interruptions $[5,20,21]$. The classification can vary from a workplace environment to another. For example, in air traffic control, communication with the pilot might be considered as an external interruption, while talking with a cabin crewmember entering the flight deck might be considered as an internal interruption [22, 23]. In general, external interruptions can be a result of alerts, notifications or environmental cues. One type of internal interruption, called self-interruptions, is related to decisions to halt a current activity to attend an alternative task owed to individual thought processes [24]. Intended breaks are not considered as interruptions. Several factors may result in interruptions in workplace environments, such as interacting with information and communication technologies, which is known as human computer interaction (HCI) [5, 20, 21], and performing general office-related activities [25-27], and multitasking. For a more detailed discussion regarding the causes of interruptions in workplace environments and their effects on human performance, refer to $[28,29]$.

\section{A. Interacting with Information and Communication Technologies}

Interacting with information and communication technologies and communicating with monitoring and control systems can result in interruptions in workplace environments $[5,20,21,30]$. In HCI, interruptions may enable performance on straightforward tasks, while preventing performance on difficult tasks [31]. Authors in [20] reported that workers may shift tasks every three minutes as a result of interruptions [20]. After a survey of 1000 senior executives, authors in [32] stated that unwanted interruptions comprise $28 \%$ of a worker's day. Authors in [33] reported that undesired disruptions cause workers to take up to $30 \%$ more time to finish the task and commit up to two times the number of errors. Authors in [34, 35] studied self-imposed interruptions in computer-based tasks, and found that it is common for people to use a number of programs/applications simultaneously. Authors in [36] studied email interruptions and their influence on people's attention. The results indicated that individuals choose tactics for realizing a task according to the particular factors of the task or objective. They suggested that email interruptions are manageable when they do not deviate a person's focus away from a central task, and do not compel the receiver to deal with the interruption. In addition, people use a wide range of different tactics for dealing with email interruptions and those strategies vary based on the circumstantial factors afforded by the task or email. Authors in [37] evaluated the use of short email messages in computer related tasks, and found that the practice of one-line electronic mail messages decreases the interruption time for both sender and receiver. Authors in [38] found that the customized settings for the notification method of incoming electronic messages, in many email clients, may result in some reduction of the computer-based interruptions. Authors in [18] investigated the use and impact of instant messaging (IM) tools in the workplace. The authors proposed that while the use of IM may result in interruptions, it can lead to enhanced communication quality and the development of a sense of trust among coworkers. Authors in [39] reported that interruptions result into a decrease in quality of work during difficult and creative writing tasks. Authors in [19] conducted experiments to evaluate the influence of IM interruptions on knowledge worker task performance. Task performance was determined using two factors, task accurateness and task completion time. The designed tasks were classified as symbolic (manipulation of distinct sets of symbols) and spatial (creating connections between sets of symbols). Their results showed that instant massaging interruptions have no effect on task accuracy, but have a significant effect on task completion time. Authors in [40] reported that a ringing phone's interruption at an inconvenient instant can be very disrupting to the present task or social condition. Authors in [41] conducted a study on cell phone usage. The investigation of 1201 incoming calls showed that most of the time "who" is calling was used $(87.4 \%)$ by persons to make cautious call handling decisions $(\mathrm{N}=834)$, contrary to the interrupter's existing local social $(34.9 \%)$ or cognitive $(43 \%)$ circumstances. 


\section{B. Performing Office-Related Activities}

Office-related activities are day-to-day tasks related to planning and scheduling, distribution and logistics, personnel, financial, record keeping and billing, and many other activities within a company. Interruptions can occur during the performance of these activities as a result of insufficient employee education (or unawareness) about interruptions and their consequences [42], noises from conversations and other offices [25-27, 38, 43], high traffic areas [44], and disturbance by visitors for staff working either on high cognitive load activities or on tasks with tight timelines [42, 43]. Authors in [42] reported that in any company, interruptions may occur as a result of insufficient employees' education regarding this matter. Thus, educating employees about may assist in decreasing their influence. The authors also reported that teaching staff about the adverse effects of interruptions results into a decline in interruptions by $30 \%$. They also reported that interruptions could occur as a result of disturbance by visitors. Thus, the authors suggested the use of "Do not Disturb" (or similar) signs in time and focus demanding workplaces. The authors' suggestion had substantial improvements in user's performance and contentment. Authors in [43] studied the preferences of staff working on critical and tight timelines, and recommended assignment of independent working space for employees working on jobs with strict deadlines. Some studies addressed noise as a widespread cause of interruptions in workplace environments [25-27, 38, 43]. Several strategies have been reported to decrease the influence of such interruptions. For example authors in [43] suggested the use of alternative sounds such as ambient background office music that could counterbalance chatty noises and control the distractions in the office. Authors in [38] reported that the use of ear buds/headphones undoubtedly restricts the different conversations and other office noises [38]. Authors in [25-27] suggested that office organization might be needed in case it is feasible to define loud and silent zones. Moreover, the degree of noise within these zones should be known. Thus it will provide a reason to move staff members so that the noise is more uniformly dispersed through the workplace.

In many workplace environments, high traffic areas may exist and can cause interruptions. Isolating these areas can reduce the impact of disruptions in the workplace [44]. Authors in [17] examined the consequences of interruption frequency, task intricacy, and individual characteristics on mental load and consequently decision-making performance on monetary tasks. The outcomes showed that task complexity and interruption frequency have significant influence on performance. Authors in [38] identified different kinds of interruptions for workplace related tasks, explored the circumstantial features near these interruptions, and identified methods that could be used to mitigate the adverse effects of interruptions. They found that most of the time interruptions occur mainly from colleagues. Disruptions are a noteworthy problem in the workplace, and most of the interruptions at all stages were associated with ontask business activities. Authors in [45] investigated the idea of users deferring interruptions at points of higher workload until times of lower workload. Their study showed that during periods of lower workload, users swapped to the interrupting task $94 \%$ of the time.

\section{INTERRUPTION MANAGEMENT STRATEGIES}

Interruptions stand as an important research area. With the advances in information and communication technologies, the amount of interruptions on day-to-day basis is also rising [38]. Interruptions are a ubiquitous component of the workplace, and have the capability to be perilous, particularly in cognitively intensive knowledge workplace environments [46]. If they are not handled in an effective and efficient way, they can lead to health, safety, and performance problems [47]. Figure 1 presents a cause and effect diagram that illustrates why interruptions take place in workplace environments.

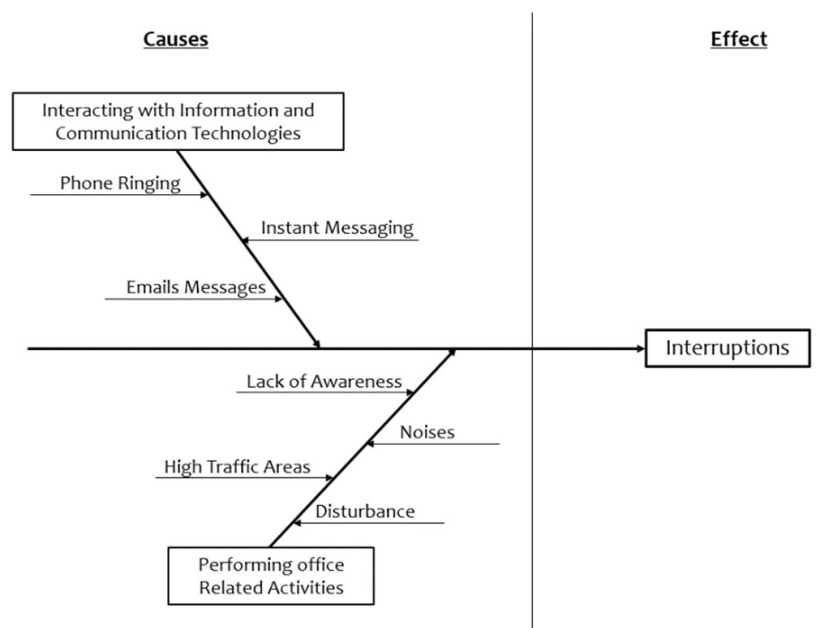

Fig. 1. A cause and effect diagram of interruptions in workplace environments

Interruptions can be controlled in several manners, including denial, postponement, and prompt partial processing [48]. Handling interruptions is a part of interruption management, which has been defined by as the detection, interpretation, and integration of interruptions within ongoing task performance [6]. The importance of having an environment with minimum interruptions effect is what makes interruption management an important issue in human multitasking environments. A task-independent Interruption Management System (IMS) was developed with an objective to interrupt users at low-workload moments in order to minimize the disruptiveness of interruptions [49]. In Interruption-Failure Modes and Effects Analysis (I-FMEA) [50], the interruptionrelated failure modes are assessed in terms of risk, worker efficiency, and patient satisfaction. This strategy helps identify interruptions that may be delayed (i.e. reflecting relatively low risk, average effect on patient satisfaction, and average additional work). Several strategies for managing interruptions can be found in the literature. For example, authors in [6] proposed a 4-stage model for interruption management: interruption detection, interruption interpretation, interruption integration, and dismiss with in-hand task performance. Authors in [51] identified four strategies for handling interruptions: (a) before starting the interruptive task complete in-hand task, (b) postpone the interruptive task so as to finish the main task (i.e. asking a caller to wait on hold), (c) recognize the matter of the interruptive task and then finish the main task 
before finalizing the interruptive task, and (d) process the interruptive task instantly, quitting the in-hand task that will be accomplished later [51]. Author in [52] proposed four different strategies for managing interruptions: (a) instantaneous, (b) planned, (c) negotiated, and (d) facilitated. Authors in [46] addressed a set of stages to handle an interruption: identifying the interruption, understanding what the interruption contains, assimilating the interruption into the present work task and then continuing with the in-hand task. Figure 2 depicts the proposed stage model for interruption management, modified from [46].

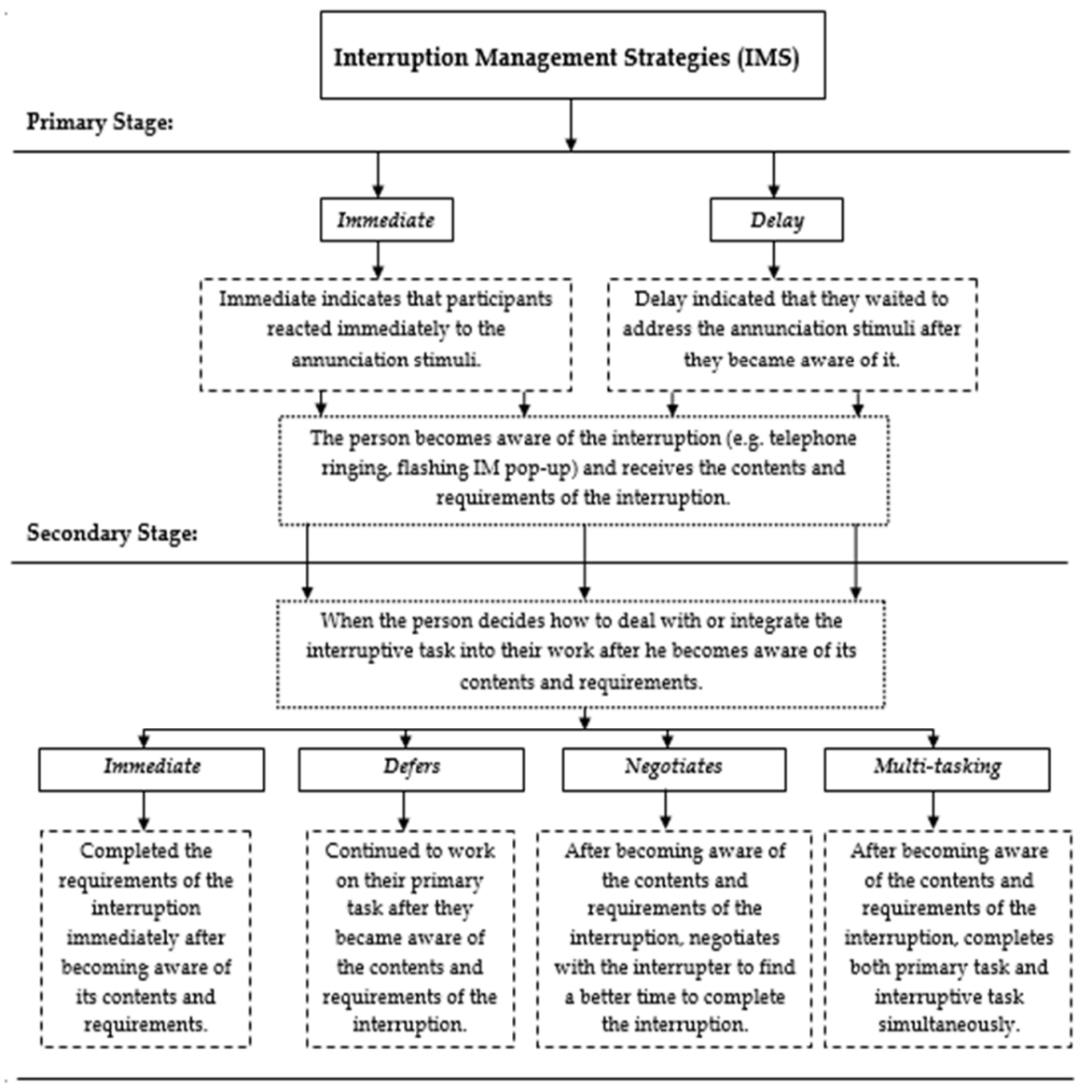

Fig. 2. Proposed stage model of interruption management strategy, modified from [46]

To manage an interruption, first there is a need to identify the aspects that make interruption an encumbrance. Next, an interruption management strategy can be applied [53]. The challenge in handling an interruption is in how to manage it in order to cause minimal harm and at the utmost advantage. The tactic must not be more disrupting than the interruption itself [54]. Table I provides a summary of literature findings pertaining to interruption management strategies that can be used as a theoretical foundation for human interruption management in workplace environments.

\section{DISCUSSION, CONCLUSIONS AND FUTURE WORK}

This paper provides a systematic review of human interruption management in workplace environments. The review concentrates on the interruption causes in workplace environments and on the strategies to handle and manage those interruptions. It starts by defining workplace environments, and introduces features of a well-designed workplace environment, and how interruptions might impact these features.
Interruptions are defined in the context of workplace environments, and interruption causes are discussed. The causes of interruptions are classified into two broad sections namely: interacting with information and communication technologies (known as $\mathrm{HCI}$ ), and performing office-related activities. In HCI there are several causes of interruptions such as phone ringing, emails, and instant messaging. In officerelated activities, there are several causes like lack of awareness, and noises from conversations and other offices, disturbances by visitors, and by high traffic areas.

Recovering from interruptions takes longer than one can think. Some interruptions may look insignificant in nature, however they have long term impact and cause delays and reduce productivity. Workplace interruptions are an inescapable problem that results into compromised efficiency, productivity, and accuracy [57]. An experimental study [58] was conducted with a hypothesis that people's productivity decreases when interrupted compared to when they have not been interrupted. The results showed that the interruptions 
reduce productivity and increase the probability of errors. Some studies showed that interruptions increase stress levels [59-61]. Authors in [62] analyzed the effect of interruptions on task performance, annoyance, and anxiety. The results revealed that interruptions have disrupting effects on both emotional state and productivity. However, some studies showed that interruptions have benefits sometimes, such as walking in nature for some time reduce stress and increases creativity, etc. [63-65].

TABLE I. SUMMARY OF LITERATURE FINDINGS IN INTERRUPTIONS MANAGEMENT

\begin{tabular}{|c|c|c|c|}
\hline Expected interruptions & Proposed procedures & $\begin{array}{l}\text { Suggestions and clarifications } \\
\end{array}$ & Source \\
\hline \multirow{2}{*}{ Emails and email messages } & Customize settings & $\begin{array}{c}\text { Various email clients have personalized settings for the reporting of inward email } \\
\text { messages. }\end{array}$ & [38] \\
\hline & $\begin{array}{l}\text { Keep them short and } \\
\text { pretty }\end{array}$ & $\begin{array}{l}\text { Encourage the use of short messages. The practice of one-line email messages decreases the } \\
\text { interruption time for both sender and receiver. }\end{array}$ & {$[37]$} \\
\hline Instant messaging & Only if necessary & $\begin{array}{c}\text { In tasks of little or modest mental load with numerous natural breakpoints, instant } \\
\text { messaging can be allowed. }\end{array}$ & {$[25,55,56]$} \\
\hline Self-imposed interruptions & $\begin{array}{l}\text { Better if working on the } \\
\text { primary task }\end{array}$ & Switching though occupied by the goal of the main task could be better. & {$[25,26,35]$} \\
\hline High traffic areas & Be aware of their impact & Isolating high traffic areas to reduce the impact of disruptions. & {$[44]$} \\
\hline \multirow[b]{3}{*}{$\begin{array}{l}\text { Noises from conversations } \\
\text { and other offices }\end{array}$} & Ear buds/headphones & The use of ear buds/headphones definitely restricts noise disturbances. & [38] \\
\hline & Background music & $\begin{array}{l}\text { The use of ambient background workplace music may balance the conversational noise and } \\
\text { control the disturbances in the workplace. }\end{array}$ & [43] \\
\hline & $\begin{array}{l}\text { Office organization and } \\
\text { restructuring }\end{array}$ & $\begin{array}{l}\text { Mounting various sound measurement devices all over the office would be achievable to } \\
\text { specify if loud and silent regions exist and their noise level. The outcomes may divulge } \\
\text { substantial differences between places and offer explanation in rearranging staff so that the } \\
\text { noise is more uniformly dispersed all through the workplace. }\end{array}$ & {$[25-27]$} \\
\hline Disturbance by visitors & "Back in 10 minutes" & $\begin{array}{c}\text { Place "Do not Disturb" (or similar) signboards in the workplace of developers/programmers } \\
\text { working on high cognitive load tasks. The use of these signs has substantial improvements } \\
\text { in user performance and satisfaction. }\end{array}$ & {$[42]$} \\
\hline $\begin{array}{l}\text { Interruptions during tasks } \\
\text { with tight timelines }\end{array}$ & Quiet working rooms & Allocate independent offices for employees working on strict timelines. & {$[42,43]$} \\
\hline $\begin{array}{l}\text { Interruptions caused by } \\
\text { unawareness }\end{array}$ & Educate staff & $\begin{array}{l}\text { Educating staff about the amount of interruptions that are taking place at all stages of the } \\
\text { company. }\end{array}$ & [42] \\
\hline
\end{tabular}

This paper describes the current approaches and strategies to identify, report, and manage interruptions. Based on these strategies, the paper proposes a stage model of interruption management that can be considered as a summary of the analyzed strategies to manage interruptions. Finally, a summary of literature findings pertaining to interruption management strategies was provided. The summarized strategies can be used as a theoretical foundation for human interruption management in workplace environments. Future research includes the empirical evaluations of the proposed strategies. Comparison studies should be conducted to determine the most suitable strategy to use for a certain environment. Moreover, such studies might be applied to different workplace environments, with the intention of assessing the efficacy of the suggested strategies.

\section{ACKNOWLEDGMENT}

This project was funded by the National Plan for Science, Technology and Innovation (MAARIFAH), King Abdulaziz City for Science and Technology, Saudi Arabia, Award Number (12-INF2574-02).

\section{REFERENCES}

[1] P. Jackson, R. Suomi, E-business and workplace redesign, Routledge, 2001

[2] J. E. Innes, D. E. Booher, "Consensus building and complex adaptive systems: A framework for evaluating collaborative planning", Journal of the American Planning Association, Vol. 65, No. 4, pp. 412-423, 1999

[3] B. A. Bettencourt, M. B. Brewer, M. R. Croak, N. Miller, "Cooperation and the reduction of intergroup bias: The role of reward structure and social orientation", Journal of Experimental Social Psychology, Vol. 28, No. 4, pp. 301-319, 1992
[4] L. B. Marques, "Interest rates and crisis: Revisiting the "Taylor rule"', SAIS Review of International Affairs, Vol. 30, No. 1, pp. 157-160, 2010

[5] Y. Miyata, D. A. Norman, "Psychological issues in support of multiple activities", User centered system design: New perspectives on humancomputer interaction, pp. 265-284, 1986

[6] K. A. Latorella, Investigating interruptions: Implications for flightdeck performance, National Aeronautics and Space Administration, 1999

[7] P. J. Hopp, C. A. P. Smith, B. A. Clegg, E. D. Heggestad, "Interruption management: The use of attention-directing tactile cues", Human Factors: The Journal of the Human Factors and Ergonomics Society, Vol. 47, No. 1, pp. 1-11, 2005

[8] A. R. Rodriguez, B. T. Karsh, "Interruptions and distractions in healthcare: Review and reappraisal", BMJ Quality and Safety, Vol. 19, No. 4, pp. 304-312, 2010

[9] J. L. Holland, A classification for occupations in terms of personality and intelligence, American Psychologist, 1959

[10] M. Lomax, "What makes a great workplace?", Dermatology Nursing, Vol. 19, No. 1, pp. 80, 2007

[11] E. Yousefian, A. Chitsaz, B. Karimpour, "Case study of effectiveness evaluation of staff training courses in Refah bank", Engineering, Technology \& Applied Science Research, Vol. 7, No. 4, pp. 1870-1873, 2017

[12] A. Hassan, K. E. Rayes, "Quantifying the interruption impact of activity delays in non-serial repetitive construction projects", Construction Management and Economics, available at: https://www.tandfonline.com/ doi/abs/10.1080/01446193.2019.1657922, 2019

[13] L. Moller, K. W. Christiansen, A. S. Mortensen, "Interruptions affect the quality of radiographic practice", Journal of Radiology Nursing, Vol. 39, No. 1, pp. 48-52, 2019

[14] G. Pozo, M. A. P. Escutia, A. Ruiz, A. Ferrando, A. Milanes, E. Cabello, R. Diaz, A. Prado, J. F. P. Regadera, "Management of interruptions in radiotherapy treatments: Adaptive implementation in high workload sites", Reports of Practical Oncology \& Radiotherapy, Vol. 24, No. 2, pp. 239-244, 2019 
[15] T. Bellandi, A. Cerri, G. Carreras, S. Walter, C. Mengozzi, S. Albolino, E. Mastrominico, F. Renzetti, R. Tartaglia, J. Westbrook, "Interruptions and multitasking in surgery: A multicentre observational study of the daily work patterns of doctors and nurses", Ergonomics, Vol. 61, No. 1, pp. $40-47,2018$

[16] S. Seshadri, Z. Shapira, "Managerial allocation of time and effort: The effects of interruptions", Management Science, Vol. 47, No. 5, pp. 611733, 2001

[17] K. A. Basoglu, M. A. Fuller, J. T. Sweeney, "Investigating the effects of computer mediated interruptions: An analysis of task characteristics and interruption frequency on financial performance", International Journal of Accounting Information Systems, Vol. 10, No. 4, pp. 177-189, 2009

[18] C. X. Ou, R. M. Davison, "Interactive or interruptive? Instant messaging at work", Decision Support Systems, Vol. 52, No. 1, pp. 61-72, 2011

[19] G. Mansi, Y. Levy, "Do instant messaging interruptions help or hinder knowledge workers' task performance?", International Journal of Information Management, Vol. 33, No. 3, pp. 591-596, 2013

[20] V. M. Gonzalez, G. Mark, "Constant, constant, multi-tasking craziness: managing multiple working spheres", in: Proceedings of the SIGCHI conference on human factors in computing systems, ACM 2004

[21] G. Mark, V. M. Gonzalez, J. Harris, "No task left behind?: examining the nature of fragmented work", Conference on Human Factors in Computing Systems, Oregon, USA, April 2-7, 2005

[22] Flight Safety Foundation, "ALAR Briefing Note 2.4. Interruptions/Distractions”, in: ALAR Tool Kit, FSF, 2000

[23] Airbus, Flight operations briefing notes: Managing interruptions and distractions, Airbus, 2004

[24] R. F. Adler, R. B. Fich, "Self-interruptions in discretionary multitasking", Computers in Human Behavior, Vol. 29, No. 4, pp. 14411449, 2013

[25] S. Gievska, R. Lindeman, J. Sibert, "Examining the qualitative gains of mediating human interruptions during HCI", 11th International Conference on Human-Computer Interaction, Las Vegas, Nevada, July 22-27, 2005

[26] S. G. Hart, L. E. Staveland, "Development of NASA-TLX (Task Load Index): Results of empirical and theoretical research", Advances in Psychology, Vol. 52, pp. 139-183, 1988

[27] R. C. O. Reilly, Y. Munakata, Computational explorations in cognitive neuroscience: Understanding the mind by simulating the brain, MIT Press, 2000

[28] B. C. Lee, V. G. Duffy, "The effects of task interruption on human performance: A study of the systematic classification of human behavior and interruption frequency", Human Factors and Ergonomics in Manufacturing \& Service Industries, Vol. 25, No. 2, pp. 137-152, 2015

[29] F. Tetard, On fragmentation of working time: A study of causes and effects of work interruptions, Abo Akademi University, 1999

[30] I. Androulidakis, G. Kandus, "Mobile phone brand categorization vs. users' security practices", Engineering, Technology \& Applied Science Research, Vol. 1, No. 2, pp. 30-35, 2011

[31] C. Speier, I. Vessey, J. S. Valacich, "The effects of interruptions, task complexity, and information presentation on computer-supported decision-making performance", Decision Sciences, Vol. 34, No. 4, pp. 771-797, 2003

[32] J. B. Spira, J. B. Feintuch, The cost of not paying attention: How interruptions impact knowledge worker productivity, Basex, 2005

[33] B. P. Bailey, J. A. Konstan, "On the need for attention-aware systems: Measuring effects of interruption on task performance, error rate, and affective state", Computers in Human Behavior, Vol. 22, No. 4, pp. 685708, 2006

[34] S. G. Hart, "Development of a multi-dimensional workload rating scale: Results of empirical and theoretical research", Human Mental Workload, Vol. 1, pp. 39-183, 1988

[35] F. Jambon, "Formal modelling of task interruptions", Conference Companion on Human Factors in Computing Systems, Vancouver, Canada, April 13-18, 1996

[36] E. Russell, L. M. Purvis, A. Banks, "Describing the strategies used for dealing with email interruptions according to different situational parameters", Computers in Human Behavior, Vol. 23, No. 4, pp. 18201837, 2007

[37] T. Jackson, R. Dawson, D. Wilson, "Reducing the effect of email interruptions on employees", International Journal of Information Management, Vol. 23, No. 1, pp. 55-65, 2003

[38] E. R. Sykes, "Interruptions in the workplace: A case study to reduce their effects", International Journal of Information Management, Vol. 31, No. 4, pp. 385-394, 2011

[39] C. K. Foroughi, N. E. Werner, E. T. Nelson, D.A. B. Davis, "Do interruptions affect the quality of work?", 57th Annual Meeting of the Human Factors and Ergonomics Society, San Diego, California, September 30-October 4, 2013

[40] E. S. D. Guzman, M. Sharmin, B. P. Bailey, "Should i call now? Understanding what context is considered when deciding whether to initiate remote communication via mobile devices", Graphics Interface Conference, Montreal, Canada, May 28-30, 2007

[41] S. Grandhi, Q. Jones, "Technology-mediated interruption management", International Journal of Human-Computer Studies, Vol. 68, No. 5, pp. 288-306, 2010

[42] R. V. Solingen, E. Berghout, F. V. Latum, "Interrupts: Just a minute never is", IEEE Software, Vol. 15, No. 5, pp. 97-103, 1998

[43] A. Furnham, A. Bradley, "Music while you work: The differential distraction of background music on the cognitive test performance of introverts and extraverts", Applied Cognitive Psychology, Vol. 11, No. 5, pp. 445-455, 1997

[44] M. Q. Patton, Qualitative evaluation and research methods, SAGE, 1990

[45] D. D. Salvucci, P. Bogunovich, "Multitasking and monotasking: The effects of mental workload on deferred task interruptions", Conference on Human Factors in Computing Systems, Georgia, USA, April 10-15, 2010

[46] E. Dawe, E. G. Toms, "The effect of interruptions on knowledge work", 7 th World Congress on the Management of eBusiness, Halifax, Canada, July, 2006

[47] C. Speier, J. S. Valacich, I. Vessey, "The influence of task interruption on individual decision making: An information overload perspective", Decision Sciences, Vol. 30, No. 2, pp. 337-360, 1999

[48] S. O. Minassian, M. J. Muller, D. Gruen, "Diverse strategies for interruption management in complex office activities", Poster submitted to CSCW, 2004, Chicago, USA, November, 2004

[49] I. Katidioti, J. P. Borst, D. J. B. D. Haan, T. Pepping, M. K. V. Vugt, N. A. Taatgen, "Interrupted by your pupil: An interruption management system based on pupil dilation", International Journal of HumanComputer Interaction, Vol. 32, No. 10, pp. 791-801, 2016

[50] L. Cure, A. Elliott, S. Nicks, "Identifying appropriate interruptionhandling strategies during healthcare care processes", IISE Transactions on Healthcare Systems Engineering, Vol. 7, No. 4, pp. 261-270, 2017

[51] H. Eyrolle, J. M. Cellier, "The effects of interruptions in work activity: Field and laboratory results", Applied Ergonomics, Vol. 31, No. 5, pp. 537-543, 2000

[52] D. C. McFarlane, "Comparison of four primary methods for coordinating the interruption of people in human-computer interaction", Human-Computer Interaction, Vol. 17, No. 1, pp. 63-139, 2002

[53] S. Zulkernain, P. Madiraju, S. I. Ahamed, "A context aware interruption management system for mobile devices", Mobile Wireless Middleware, Operating Systems, and Applications, pp. 221-234, 2010

[54] D. C. McFarlane, K. A. Latorella, "The scope and importance of human interruption in human-computer interaction design", Human-Computer Interaction, Vol. 17, No. 1, pp. 1-61, 2002

[55] A. F. Cameron, J. Webster, "Unintended consequences of emerging communication technologies: Instant messaging in the workplace", Computers in Human Behavior, Vol. 21, No. 1, pp. 85-103, 2005

[56] R. D. O'Donnell, F. T. Eggemeier, "Workload assessment methodology", Handbook of Perception and Human Performance, Vol. 2, pp. $1-49,1986$

[57] J. S. Zide, M. J. Mills, C. S. Denning, C. Sweetapple, "Work interruptions resiliency: Tow ard an improved understanding of employee 
efficiency", Journal of Organizational Effectiveness: People and Performance, Vol. 4, No. 1, pp. 39-58, 2017

[58] D. P. Brumby, C. P. Janssen, G. Mark, "How do interruptions affect productivity?", Rethinking Productivity in Software Engineering, pp. 85107,2019

[59] K. Kushlev, E. W. Dunn, "Checking email less frequently reduces stress", Computers in Human Behavior, Vol. 43, pp. 220-228, 2015

[60] K. Kushlev, J. Proulx, E. W. Dunn, ““'Silence your phones”: Smartphone notifications increase inattention and hyperactivity symptoms", CHI Conference on Human Factors in Computing Systems, San Jose, USA, May 7-12, 2016

[61] G. J. Mark, S. Voida, A. V. Cardello, "“A pace not dictated by electrons": An empirical study of work without e-mail", Conference on Human Factors in Computing Systems, Texas, USA, May 5-10, 2012

[62] B. P. Bailey, J. A. Konstan, J. V. Carlis, The effects of interruptions on task performance, annoyance, and anxiety in the user interface, University of Minnesota, 2001

[63] M. Czerwinski, E. Horvitz, S. Wilhite, "A diary study of task switching and interruptions", Conference on Human Factors in Computing Systems, Vienna, Austria, April 24-29, 2004

[64] J. M. Hudson, J. Christensen, W. A. Kellogg, T. Erickson, “"I'd be overwhelmed, but it's just one more thing to do": Availability and interruption in research management", Conference on Human Factors in Computing Systems, Minneapolis, USA, April 20-25, 2002

[65] J. Jin, L. A. Dabbish, "Self-interruption on the computer: A typology of discretionary task interleaving", Conference on Human Factors in Computing Systems, Boston, USA, April, 2009 